\title{
TÉCNICAS HISTOLÓGICAS APLICADAS A LA DOCENCIA EN MORFOLOGÍA
}

Roy Riascos, M.D. *, Diego Aldana, O.D. **, Miguel Ruiz, M.D. ***, Francisco Villa, O.D. **

\section{Resumen}

Se presenta la descripción de una técnica utilizada en histología como lo es la parafinización, aplicada a conservación de piezas de morfología macroscópica. Esta técnica utiliza materiales que se encuentran en cualquier laboratorio de histología, obteniendo como resultado piezas que se pueden manipular sin guantes y sin las desventajas del formol.

\section{Introducción}

Existen diversos medios para facilitar el aprendizaje de la morfología y entre ellos se encuentra el grupo de modelos tridimensionales que ayudan a comprender el volumen, forma y las relaciones espaciales. Dentro de este grupo de modelos existen aquellos que son preparados a partir de material biológico utilizando técnicas basadas en principios de preparaciones histológicas.

Un grupo de docentes dedicado a la morfología humana ha buscado implementar estas técnicas histológicas de tal forma que puedan ser aprovechadas en la docencia de las ciencias biológicas, con la creación de estos modelos a partir de tejido orgánico. Estos procedimientos pueden ser de utilidad para complementar el perfil profesional de los estudiantes de la facultad de citohistotecnología. La parafinización es una técnica de la histología básica que puede utilizarse para conservar piezas microscópicas útiles para la docencia. El objetivo es presentar un método de poca difusión en nuestro medio, utilizando materiales de fácil acceso.

Fundación Universitaria de Ciencias de la Salud. Hospital de San José, Bogotá, D.C.

* Fundación Universitaria de Ciencias de la Salud. Universidad El Bosque, Bogotá, D.C.

***Universidad El Bosque. Bogotá, D.C.
El grupo de docentes lo conforman médicos y odontólogos dedicados a la enseñanza de la morfología en diferentes facultades; profesionales que han buscado complementar la enseñanza con la puesta a punto de técnicas para la creación de material complementario de docencia.

La morfología moderna parte del concepto de lograr la aproximación del estudiante al conocimiento, mediante diversos métodos. La parafinización permite la manipulación de piezas en forma dinámica sin tener que limitarse a una sala de disección y, así, complementar otros métodos como los atlas, textos y la multimedia en el proceso de autoaprendizaje.

Los elementos visuales cumplen un papel fundamental en la instrucción, permitiéndole a estos modelos tridimensionales superar los modelos bidimensionales, como sucede con las diapositivas en donde el estudiante debe imaginar el volumen, dificultando la comprensión. Estos modelos volumétricos pueden suplir, en ciertos casos, incluso las disecciones cuando estas no se puedan realizar en la enseñanza de la morfología, como lo sugiere el comité de expertos de la Organización Panamericana de la Salud y la Organización Mundial de la Salud. 
La conservación de piezas anatómicas es básica como parte complementaria de la enseñanza. Para el efecto, se han elaborado diversas técnicas, de las cuales las más difundidas son la formolización, la parafinización y la plastificación.

En los actuales momentos la parafinización es una técnica poco difundida, pero que permite la preservación a largo plazo de material biológico, especialmente tejidos blandos con gran contenido de agua, que son muy susceptibles a la putrefacción. Con la proliferación de nuevas facultades de ciencias de la salud y la necesidad de la educación básica primaria y secundaria de complementar sus estudios con material volumétrico, se ve la necesidad del entrenamiento de personal en técnicas que permitan la elaboración de este material.

\section{Objetivos}

Los objetivos del trabajo son: presentar una técnica poco difundida en nuestro medio, utilizando materiales de fácil acceso; exponer técnicas basadas en princippios histológicos que pueden ser aplicadas a morfología macroscópica y preservar material biológico de forma perecedera.

\section{Materiales y métodos}

Los materiales empleados en el presente trabajo incluyeron material biológico (anatómico humano) compuesto por cerebro, tallo cerebral, cerebelo, riñón, pulmón y corazón. Los materiales químicos utilizados fueron formol a $20 \%$, alcohol etílico, xilol y parafina de baja fusión; además se necesitaron otros materiales anexos como toallas de papel, horno de incubadora, recipientes (metálicos y plásticos) de diferentes tamaños, pinzas, guantes, cuchillos y espátulas.

\section{Procedimiento}

Durante la selección y preparación del material anatómico, fueron escogidos cerebros obtenidos mediante convenio con el Instituto de Medicina Legal y Ciencias Forenses, los cuales deben encontrase en buen estado.
Para la fijación de las piezas se utilizó formaldehído a $20 \%$ por una semana, encontrándose el cerebro sostenido por una gasa en forma de "hamaca" para conservar la forma anatómica. Si se desea se puede agregar un buffer para lograr un $\mathrm{pH}$ de 7.3, similar al del plasma.

Posteriormente sigue la disección para retirar con pinza fina las leptomeninges y vasos sanguíneos. Hay que tener especial cuidado con los orígenes aparentes de los nervios craneanos. Algunas piezas pueden ser cortadas utilizando un cuchillo afilado pero nunca antes de retirar las leptomeninges ya que la presencia de estas puede desgarrar partes del corte.

En la fase de deshidratación, las piezas fueron fijadas en un recipiente con alcohol etílico a $70 \%$ durante una semana: al término de este tiempo se retira el alcohol y se remplaza por otro de una concentración 5\% mayor y así sucesivamente por periodos de una semana hasta llegar a una concentración de alcohol absoluto.

Para el aclaramiento, una vez deshidratada la pieza se procede a sumergirla en una solución saturada de xilol (xilol puro) por una semana, al cabo de la cual se cambia dicha solución, repitiendo el proceso dos veces más (Figura 1).

Para disminuir los costos y facilidades de consecución de materiales se ha utilizado 'thinner' industrial sin haber hecho la morfometría correspondiente.

Para la imbibición, se derrite parafina histológica de baja fusión $\left(46^{\circ} \mathrm{C}\right)$ dentro de un recipiente metálico en un horno/incubadora hasta alcanzar su punto de fusión. Posteriormente se incluye la pieza en este recipiente y se deja en el horno por una semana, conservando la temperatura de fusión. Luego se cambia la parafina repitiendo el mismo proceso, con el fin de eliminar los restos del aclarador y mejorar las características de dureza.

Al retirar del horno la pieza, se deben remover los excesos de parafina con una toalla de papel con el fin de que no vayan a cubrir los detalles de la estructura. Posteriormente se deja secar la pieza a temperatura 


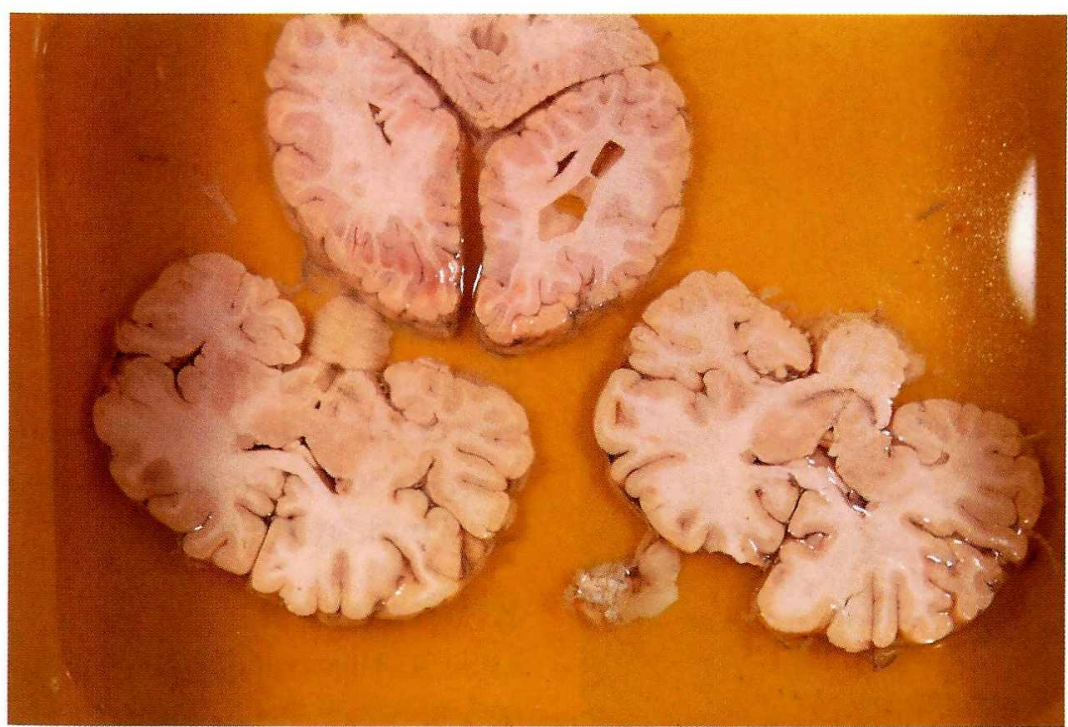

Figura 1. Piezas de cortes coronales de cerebro en recipiente con xilol, durante el proceso de parafinización.

ambiente sosteniéndola, tratando de preservar su forma original y evitando retracciones. La pieza quedará totalmente endurecida, conservando los detalles de la configuración externa e incluso la diferenciación de las sustancias gris y blanca.

\section{Resultados}

Los resultados obtenidos con el uso de la parafinización, para preservar las piezas histológicas son satisfactorios. Los especímenes preparados muestran un grado elevado de conservación y permiten apreciar los accidentes anatómicos. Por ejemplo, en el caso del tallo cerebral se aprecian las diferentes estructuras macroscópicas y la emergencia de los pares craneanos, mientras que en los cortes coronales de cerebro, se conserva una clara diferencia entre la coloración de la sustancia gris y la sustancia blanca, así como la preservación del espacio de los ventrículos laterales (Figuras 2 y 3).

\section{Discusión}

Mediante la técnica presentada, se permite la preservación del sistema nervioso de manera imperecedera, con ventajas para obviar las limitaciones impuestas por el formol, como la manipulación de las piezas con guantes, además del olor y de la toxici- dad; asimismo, conserva las ventajas de longevidad de las piezas, su capacidad de traslado y el acceso de este material en el anfiteatro y fuera de él.

En un futuro, se podría elaborar una colección estándar y crear también series secuenciales que, en conjunto, reconstruyen y permiten identificar, tanto desde el punto de vista espacial como tridimensional, las diferentes partes del sistema nervioso; material que, con facilidad, puede llevarse a las aulas de clase.

Se considera la parafinización como una técnica excelente para la definición de los accidentes anatómicos macroscópicos externos como en el caso del tallo cere-

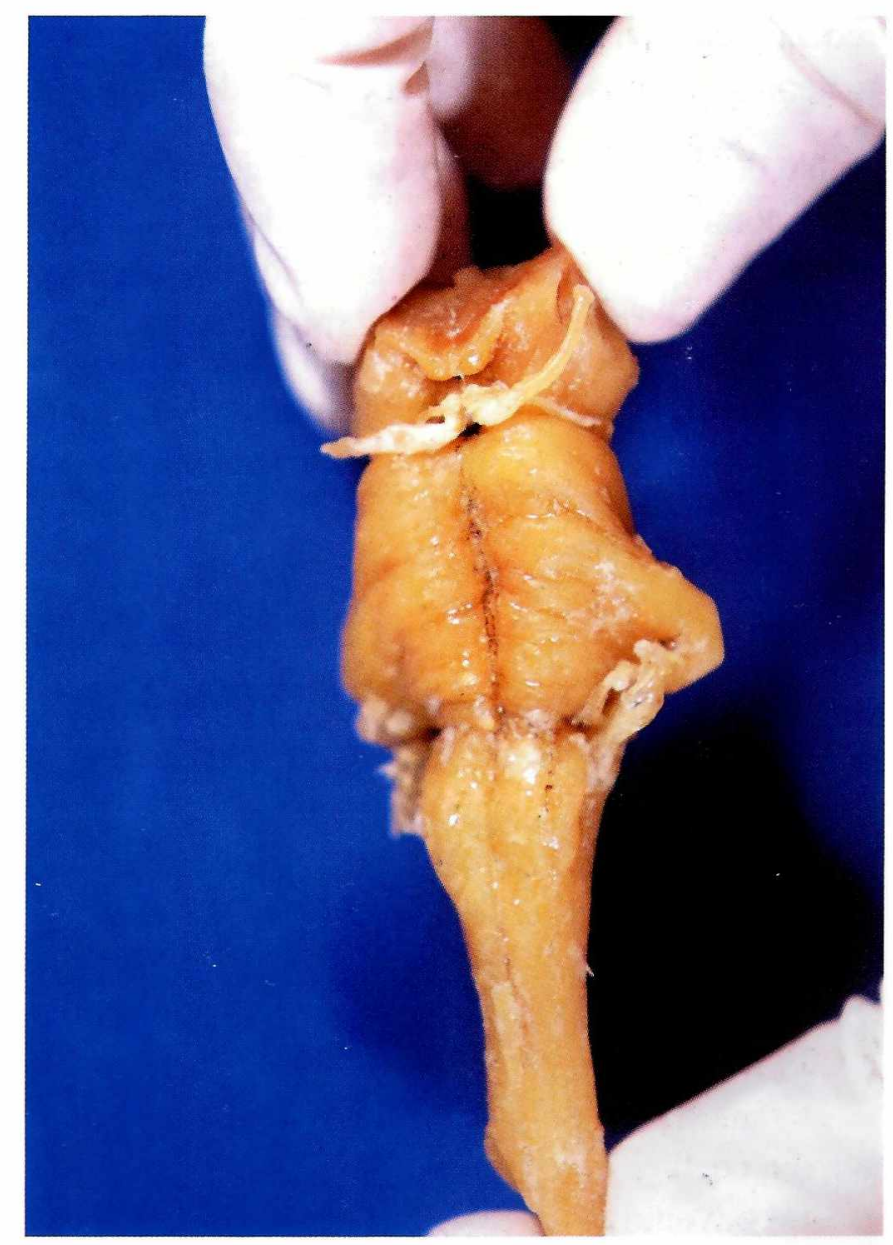

Figura 2. Tallo cerebral parafinizado. Puede observarse la conservación de los accidentes anatómicos macroscópicos. 


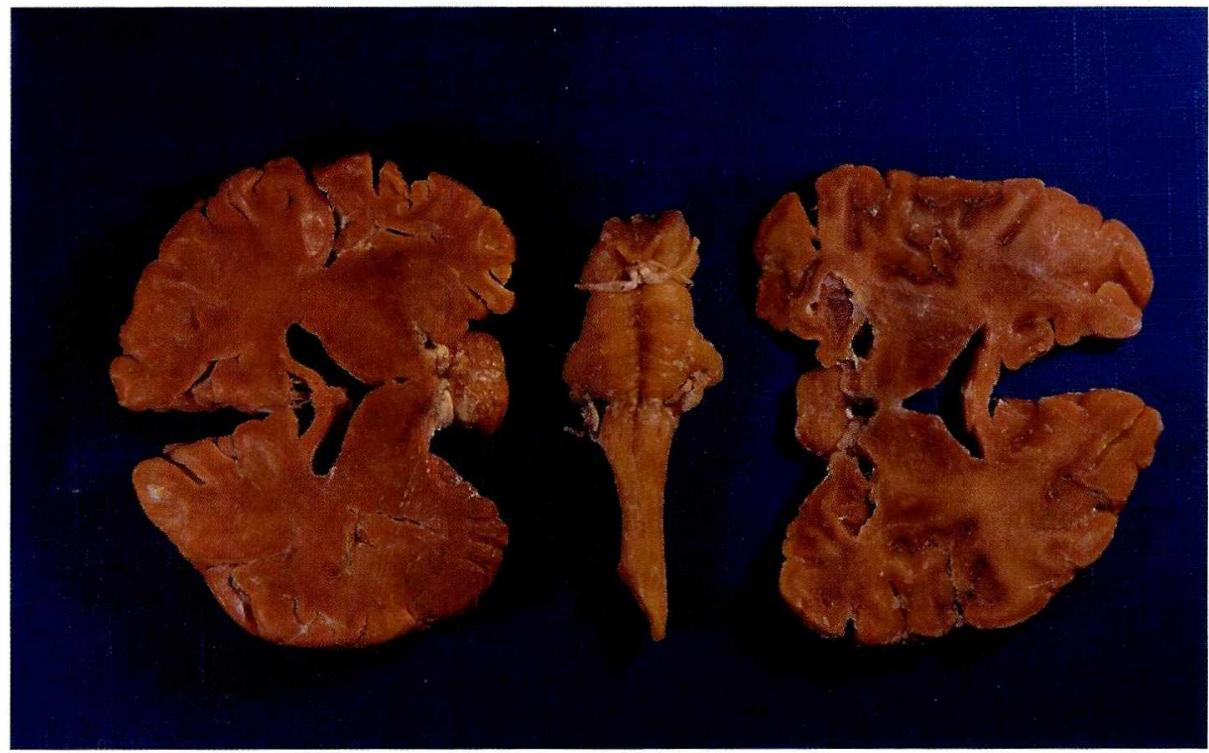

Figura 3. Tallo cerebral y cortes coronales de cerebro parafinizados. En estos últimos se observa una clara diferencia entre la sustancia gris y la sustancia blanca, así como la conservación de los surcos y circunvoluciones. za al trauma, por lo que puede fragmentarse.

Esta propuesta puede ser tomada en cuenta por los comités de currículo para su inclusión dentro de la formación, ampliando su perfil profesional en un país donde cada vez es más importante la preservación de material biológico a largo plazo.

\section{Bibliografía}

Lillie R. Histopathologic technique and practical histochemistry. $3^{\text {rd }}$ Edition, Louisiana State University, 1965. 32-61-605.

Antonetti C. Preparación de cortes de sistema nervioso central para uso simultáneo macroscópico y microscópico en la docencia. Revista de la Sociedad Venezolana de Morfología 1995; 1(1): 30-32.

Plaza Izquierdo YJ. Técnicas para cortes grandes del sistema nervioso central, en atlas de disección por regiones. Barcelona. Ed. Salvat, Mallorca. 1969. 214-216.

Correspondencia:

riascosr@1ycos.com

miguelruiz@hotmail.com casos de la sustancia blanca y la fragilidad de la pie-

\section{FUNDACIÓN UNIVERSITARIA DE CIENCIAS DE LA SALUD (FUCS)}

\section{CURSO PREUNIVERSITARIO PRIMER SEMESTRE}

Informes 2779685-2015147-2019561

Telefax: $3513375-2019561$

E-mail: fucsalud@ colomsat.net.co 